\title{
SIMULTANEOUS TESTING OF A PARABOLIC DISH CONCENTRATED PCM AND NON-PCM SOLAR RECEIVER
}

\section{R. SENTHIL \& M. CHERALATHAN}

Department of Mechanical Engineering, SRM University, Kattankulathur, Chennai, India

\begin{tabular}{l}
\hline ABSTRACT \\
A simultaneous test method is proposed, for evaluating the effect of phase change material (PCM) in the \\
concentrated solar receiver, under similar operating conditions. A $16 \mathrm{~m}^{2}$ parabolic dish concentrator is employed, to \\
concentrate the solar rays on the receiver. D-Mannitol is selected, based on the temperature region of the receiver. The \\
mass flow rate of heat transfer fluid (HTF) is $90 \mathrm{~kg} / \mathrm{h}$. The PCM integrated receiverensuresa uniform thermal output, \\
during sudden discontinuity of solar radiation for a few to several minutes, when compared to non-PCM receiver. The \\
simultaneous testing of PCM and non-PCM solar receiver concept is successfully implemented in this work. \\
KEYWORDS: Solar Receiver, Parabolic Dish, Simultaneous Testing \& Integrated PCM
\end{tabular}

Received: Sep 19, 2017; Accepted: Oct 09, 2017; Published: Oct 30, 2017; Paper Id: IJMPERDDEC20178

\section{INTRODUCTION}

Several concentrated solarreceivers for concentrating collectors are extensively investigated over the past few decades. The parabolic dish concnetrator (PDC), with integrated storage at the focus of PDC was numerically studied using Ray-tracing method, by Tao et al. [1]. The solar receiver consisted of many heat transfer tubes. HTF flowed through tubes and shell side was filled with PCM. Receiver is filled with PCM, to act as the collector as well as storage [2]. Ashmore and Simeon [3], investigated the performance of a dish solar concentrator, using energy and exergy efficiencies. Non-uniform temperature distribution has been observed on the solar receiver of a $16 \mathrm{~m}^{2}$ Scheffler reflector and a modified HTF path, also suggested for heat absorption [4]. Further, the effect of PCM in the receiver, with improvement in exergetic performance and the uniform temperature were determined $[5,6]$.

The effect of open and closed loop of HTF was compared, with respect to exergy efficiency was reported by Senthil and Cheralathan [7], and the exergy output of the open loop was better than recirculation of HTF. Vinod et al. [8], determined convection heat loss from a cavity receiver. The natural heat transfer enhancemnt of PCM, energy and exergy analysis of PCM integrated solar receiver, effect of size of PCM container [9 -13]. The effect of HTF input conditions, on the thermal performance of PDC is investigated statisticallly and inlet temperature of HTF has been found, with the most influencing parameter [14].

The review of the recent advancements in the high temperature solar receivers and solarthermal battery concept are discussed[15, 16]. The design factors of PDC and parametric analysis of operating paramers of PDC are discussed [17, 18]. Effect of PCM in solar collector and in building envilopes are discussed [19]. The testing of two receivers under similar operating conditions, is the challenge in a large scale solar collectors. The receiver with PCM was not much addressed in literature, for compensating a short time unavailability of radiation and improved 
heat flux.

Thermal storage capacity is useful, for all applications requiring uniform heat supply like solar cooking, preheating of fuels and heat treatment. It was found that, sugar alcohols are promising PCM candidates, with their high energy density and melting temperature range of $100-180^{\circ} \mathrm{C}$. The addition of more metal fins, may provide more uniform temperature inside; however, it will increase the weight of receiver. The use of PCM in the solar receiver may smoothen the thermal output, under varying solar radiation and act as a thermal battery for heating applications. PCM is aimed to achieve output temperature around $100^{\circ} \mathrm{C}$, during short time cloudy conditions. The simultaneous testing of the receiver with PCM is investigated, in outdoor testing and the improvements are reported in this study.

\section{MATERIALS AND METHODS}

A $16 \mathrm{~m}^{2}$ PDC with solar grade mirrors of 0.9 reflectivity (Thermax Ltd, Pune, India), is used in this study. The solar tracking of the PDC is a two-way axis mechanism. The specifications of the paraboloidal dish have been explained in the authors' earlier work $[4,5]$. The test site is SRM University, Chennai $\left(13^{\circ} \mathrm{N}, 80^{\circ} \mathrm{E}\right)$. The external diameter and width of the receiver were $406 \mathrm{~mm}$ and $100 \mathrm{~mm}$, respectively. The actual concentration ratio was around ninety. The receiver was fixed at a focal distance of $2.5 \mathrm{~m}$, from the dish. The simultaneous test method was proposed, to test the effectiveness of each receiver using PCM. Table 1 shows the thermal properties of PCM.

Table 1: Thermophysical Properties of PCM

\begin{tabular}{|l|l|}
\hline \multicolumn{1}{|c|}{ Properties } & \multicolumn{1}{c|}{ D-Mannitol } \\
\hline Chemical formula & $\mathrm{C}_{6} \mathrm{H}_{14} \mathrm{O}_{6}$ \\
\hline Melting point, $\left[{ }^{\circ} \mathrm{C}\right]$ & 166 \\
\hline Melting enthalpy, $[\mathrm{kJ} / \mathrm{kg}]$ & 326 \\
\hline Specific heat, $[\mathrm{kJ} / \mathrm{kg} \mathrm{K}]$ & $1.7(\mathrm{~s}), 2.4(1)$ \\
\hline Thermal conductivity, $[\mathrm{W} / \mathrm{mK}]$ & 0.279 \\
\hline Density, $\left[\mathrm{kg} / \mathrm{m}^{3}\right]$ & 1520 \\
\hline
\end{tabular}

Figure 1, shows the schematic layout of the PDC experimental test setup. Both receiver sections are separated with $30 \mathrm{~mm}$ thick glass wool insulation. The insulation between the two receivers was made, to avoid heat interaction between the sections. Rectangular thin fins are fixed on the incident surface. Both sections of receiver, fabricated with geometrically similar fins, but one side was with PCM and the other was without PCM. In the PCM integrated side, an enclosure was fixed over the fins, to accommodate the PCM of $5 \mathrm{~kg}$. The thickness of PCM around fins and receiver plate is $25 \mathrm{~mm}$ thickness. HTF is allowed to flow at a uniform rate, over the PCM housings, in PCM side and directly over the fins on the another side. The sectional views of the receiver is shown in Figure. 2 


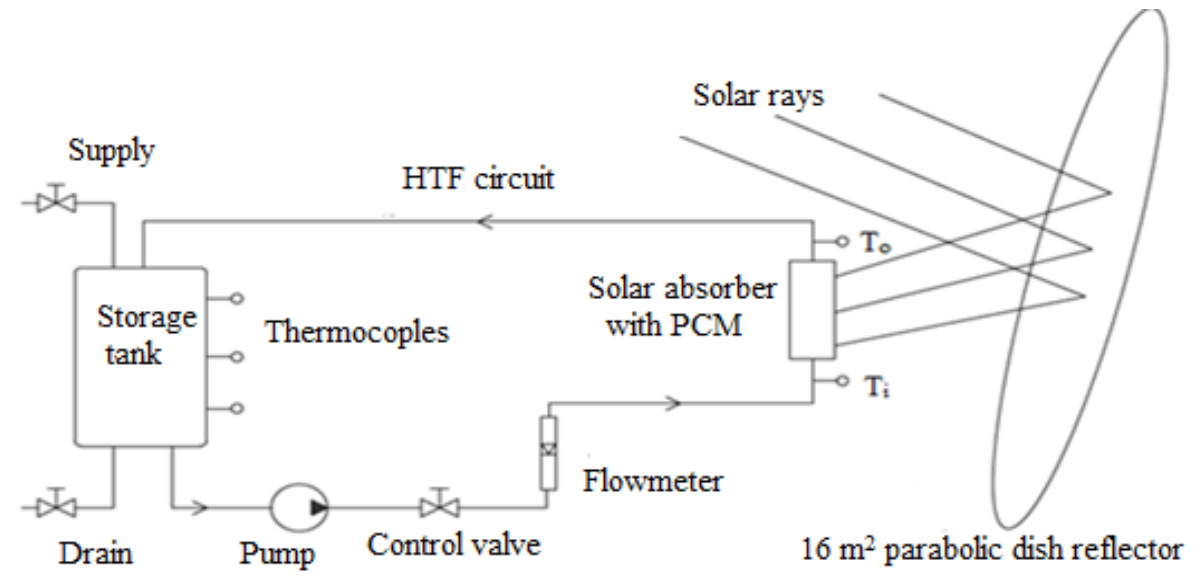

Figure 1: Schemtaic Layout of Parabolic Dish Collector and Receiver

The simultaneous test receiver is tested in outdoor under the same ambient, wind and solar radiation conditions. HTF flow direction is upwards in the receiver. The black coated receiver (absorptivity of 0.85 , emissivity of 0.15 ) is fitted with thermocouples. It was ensured that, both receiver surfaces were subjected to similar concentrated radiation, by dailytracking mechanism. The HTF flow is regulated same on both the receiver sections, through flow regulating valves. The thermal performance calculations are carried out with the experimental data.

The HTF heat gain $\left(Q_{u}\right)$ was given as in Equation. (1),

$$
Q_{u}=\dot{m} C_{p}\left(T_{o}-T_{i}\right)
$$

Where, $\mathrm{C}_{\mathrm{p}}$ - specific heat, $\dot{m}$ - mass flow rate, $\mathrm{T}_{\mathrm{i}}$ and $\mathrm{T}_{\mathrm{o}}$ - inlet and outlet temperature of HTF.

Instantaneous efficiency $(\eta)$ of the receiver was determined from the HTF heat gain and the incident solar energy, on the PDC from Equ. (2),

$$
\eta=\frac{Q_{u}}{A_{c} I_{b}}
$$

Where, $I_{b}$ - solar irradiance, $A_{c}$ - reflector aperture area.

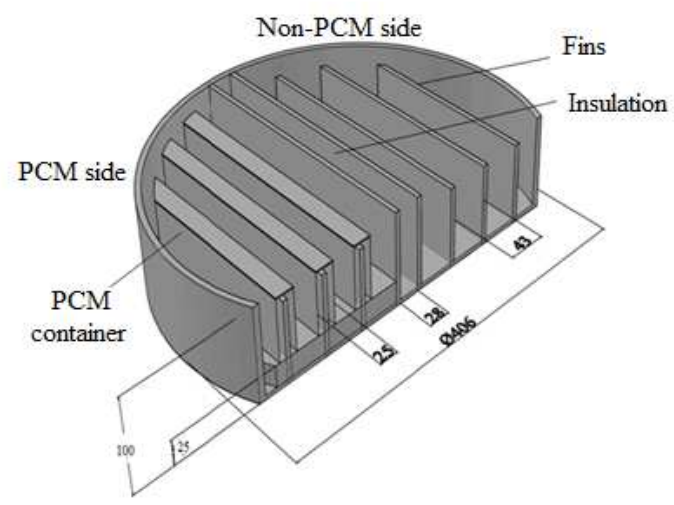

Figure 2: Sectional View of Simultaneous Test Receiver With and Without PCM

The heat stored in the PCM is expressed as : 


$$
Q_{s t}=m_{p c m}\left[\int_{T_{i}}^{T_{m}} C_{p_{s}} d T+H+\int_{T_{m}}^{T_{f}} C_{p l} d T\right]
$$

Where, $C_{p}$ - the specific heat, $d T$ - temperature range and $\mathrm{H}$-latent heat.

\section{RESULTS AND DISCUSSION}

During the outdoor experiments, quasi-steady state testing were conducted as per test standards of ASHRAE 93, in April 2017 at clear sky. HTF flow rates were controlled by control valve connected to flow meter, for the solar receiver. The liquid phase of HTF was considered, as per standard test requirements. Heating of 110 liters water from room temperature to boiling point was considered. The solar beam intensity is observed as $600-780 \mathrm{~W} / \mathrm{m}^{2}$. The wind speed is 0 $-2.5 \mathrm{~m} / \mathrm{s}$. The ambient temperature is 32 to $34^{\circ} \mathrm{C}$.

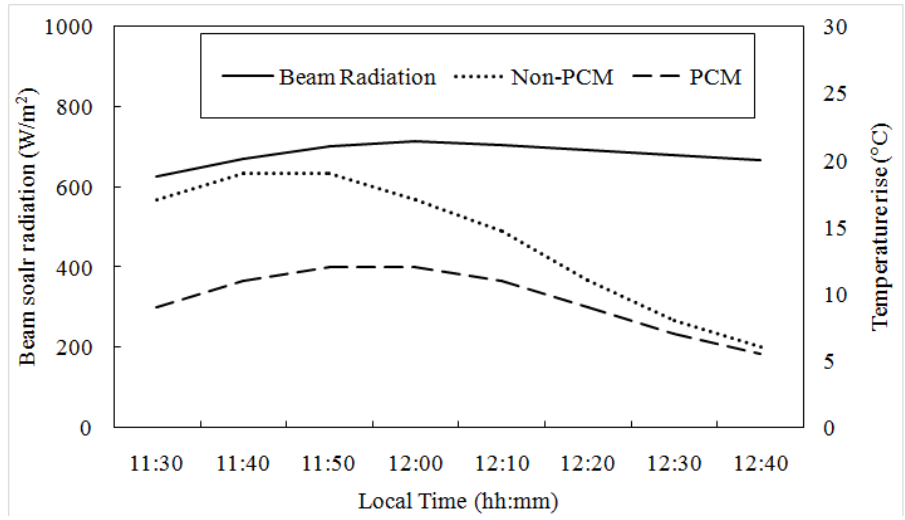

Figure 3: Variation of Receiver Surface Temperature for HTF Mass Flow Rate 70 kg/h

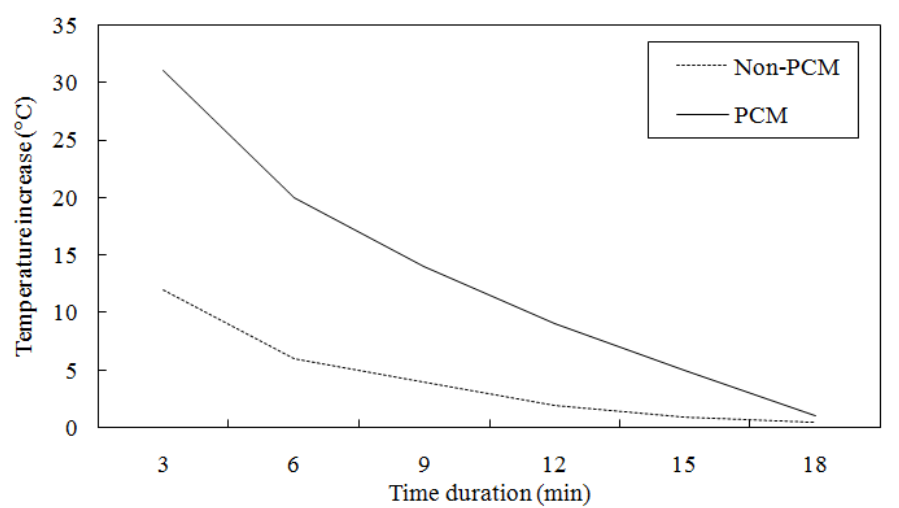

Figure 4: Temperature Rise of Water Across the Non-PCM and PCM Receiver

The receiver temperatures and HTF temperatures were logged with a datalogger. The receiver surface temperature for both, receiver surfaces with and without PCM are depicted in Figure.3. The temperature of the receiver with PCM was observed to be lower than that of the receiver, without PCM. However, the receiver with PCM was observed to have a uniform surface temperature, for HTF flow rate of $90 \mathrm{~kg} / \mathrm{h}$. During the recirculation of HTF, through both the receivers, the difference of HTF outlet temperature was significant, but after thirty minutes of operation, the difference became negligible. The average beam radiation was around $685 \mathrm{~W} / \mathrm{m}^{2}$. Both the receivers were suddenly defocused by changing the traction, and the observed temperature trend of the HTF was depicted in Figure. 4. 


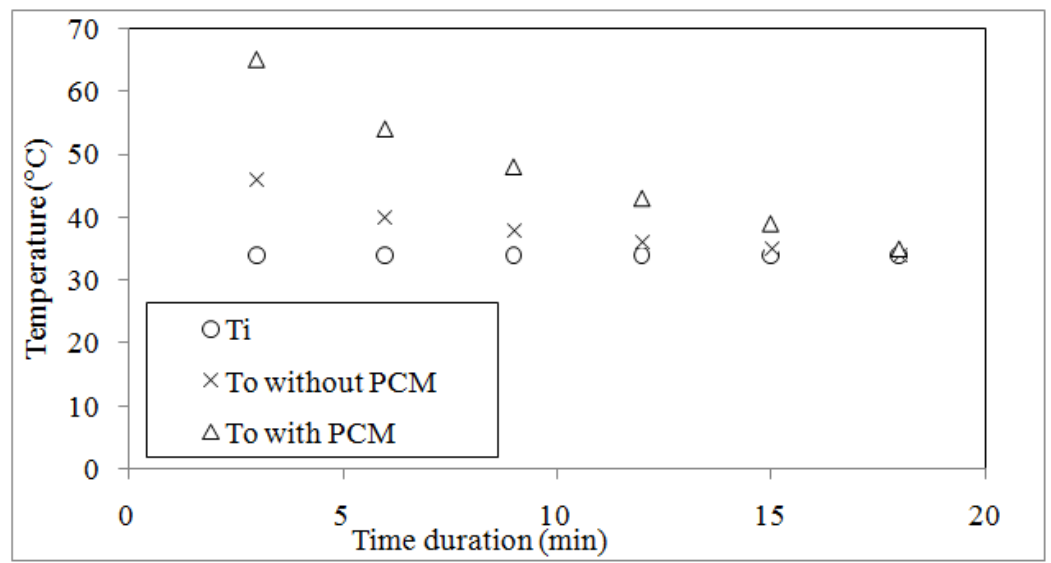

Figure 5: Comparison of Thermal Storage Capacity of Receiver With and Without PCM during Simultaneous Test with HTF Mass Flow Rate 90 kg/h.

Table 2: Uncertainty Analysis

\begin{tabular}{|l|c|}
\hline \multicolumn{1}{|c|}{ Property } & Uncertainty \\
\hline Temperature & $\pm 1 \%$ \\
\hline Solar radiation & $\pm 3 \%$ \\
\hline Wind speed & $\pm 1 \%$ \\
\hline Mass flow rate & $\pm 1 \%$ \\
\hline
\end{tabular}

The receiver with PCM inertia was 50\% more time, than the receiver without PCM. The energy stored by the PCM was, due to sensible and latent heat of the PCM. $1.1 \mathrm{~kg}$ of PCM stored was equivalent to around $400 \mathrm{~kJ}$. The complete melting of PCM was observed, for radiation above $600 \mathrm{~W} / \mathrm{m}^{2}$; the sensible and latent heating occurs within the PCM. The thermal buffering effect was enhanced by the PCM, for 8-12 minutes. Eventhough, the thermal storage capacity due to steel mass was the same for both sections and it was enhanced further, with the presence of PCM (figure. 5). Table 2 indicates the measurement uncertainties. The uncertainty in thermal efficiency is calculated by the root mean square method.

The uncertainty in the experimental energy and exergy efficiency, is within the significant level. Thus, the testing of simultaneous testing of two receiver configurations is oberved, with the similar time taken for reaching the boiling point of water. The enhanced thermal energy density of the receiver, with PCM is observed in this study. The thermal management of short time unavailability of solar energy, due to passing clouds and the possibility of later use, for several heating applications are demostrated.

\section{CONCLUSIONS}

Solar radiation of more than $600 \mathrm{~W} / \mathrm{m}^{2}$ is found useful, for quick charging of the PCM and improved useful heat transfer to the HTF. The successful use of a single PDC with similar radiation and ambient conditions, to test the effect of PCM in the receiver has been studied, effectively. The comparative testing under similar conditions considerably, reduces the time of repeatability of the outdoor experiments. Thermal storage densityis enhanced, with PCM in the receiver.

Such receivers are supplying continuous thermal output, during the short period of poor radiation, like cloud cover and passing clouds, during the day. Further, the PCM receivers are more useful than the non-PCM solar receivers, regarding the later use or remote applications. 


\section{ACKNOWLEDGEMENTS}

The author would like to acknowledge, with gratitude Thermax Ltd, Pune, India and SRM University, Kattankulathur, Chennai, India, for providing the PDC research facility.

\section{REFERENCES}

1. Tao, Y. B., Y. L. He, F. Q. Cui, C. H. Lin, "Numerical study on coupling phase change heat transfer performance of solar dish collector”, Solar Energy, 90 (2013), pp. 84-93.

2. Arunasalam, A., Anjan, R., B. Srivatsa, R. Senthil. Thermal Performance Analysis on Solar Integrated Collector Storage. UARJ, 1 (2), 2012, 2278-1129.

3. Ashmore Mawire, Simeon H. Taole, "Experimental energy and exergy performance of a solar receiver for a domestic parabolic dish concentrator for teaching purposes", Energy for Sustainable Development, 19(2014), pp. 162-169.

4. Senthil $R$ and Cheralathan M. Effect of non-uniform temperature distribution on surface absorption receiver in parabolic dish solar concentrator. Thermal Science, 21 (5), 2017, pp. 2011-2019.

5. Senthil, R., Cheralathan, M., "Effect of PCM in a solar receiver on thermal performance of parabolic dish collector", Thermal Science (2016). doi: 10.2298/TSCI150730007S,

6. Ramalingam Senthil, ChinmayaRath, Mukund Gupta, Enhancement of Uniform Temperature Distribution on the Concentrated Solar Receiver with Integrated Phase Change Material, International Journal of Mechanical Engineering and Technology, 8 (9), 2017, pp. 315-320.

7. Ramalingam Senthil, Marimuthu Cheralathan, Effect of Once-through and Recirculated Fluid Flow on Thermal Performance of Parabolic Dish Solar Receiver, Indian Journal of Science and Technology, 9 (2016), 33, pp. 1-5.

8. Vinod. S., Prashant. D., Rupesh Gawande, Experimental and numerical analysis of convective heat losses from spherical cavity receiver of solar concentrator, Thermal Science. (2015) Doi: 10. 2298 /TSCI150601165S.

9. $R$ Senthil, $M$ Cheralathan, Natural heat transfer enhancement methods in phase change material based thermal energy storage, International Journal of ChemTech Research, 9 (5), 2016, 563-570.

10. R. Senthil, and M. Cheralathan, Energy and exergy analysis of a parabolic dish concentrated solar receiver with integrated PCM, International Journal of Advance Research in Science and Engineering, 5 (10), 2016, pp. 117-121.

11. R. Senthil, M. Cheralathan, Effect of container size on thermal performance of sugar alcohol (D-Mannitol) in concentrated solar receiver, International Journal of Chemical Sciences, 14 (4), 2016, pp. 2349-2357.

12. R. Senthil. P. Sundaram, Manish Kumar, V. Avinash, "Effect of integrated phase change material on thermal performance of the point focus concentrated solar receiver", International Journal of Pure and Applied Mathematics, 114 (12), 2017, pp. 135 143.

13. Khalil Anwar, M., Yilbas, B. S., Shuja, S. Z., A thermal battery mimicking a concentrated volumetric solar receiver, Applied Energy, 175, 2016, pp. 16-30.

14. R. Senthil, S. Prabhu and M. Cheralathan, Effect of Heat Transfer Fluid Input Parameters on Thermal Output of Parabolic Dish Solar Receiver Using Design of Experiment Techniques, International Journal of Mechanical Engineering and Technology 8(8), 2017, pp. 1148-1156.

15. R. Senthil, Recent Developments in the Design of High Temperature Solar Receivers, International Journal of Mechanical Engineering and Technology, 8(8), 2017, pp. 1223-1228.

16. Yilbasa B. S., and Khalil Anwar, M., Design of a mobile thermal battery and analysis of thermal characteristics, Journal of 
Renewable and Sustainable Energy, 8, 2016, 024102.

17. R. Senthil and P. Sundaram, Effect of Phase Change Materials for Thermal Management of Buildings, International Journal of Civil Engineering and Technology, 8(9), 2017, pp. 761-767.

18. Hafez, A. Z., Ahmed Soliman, El-Metwally, K. A., and Ismail, I. M., Design analysis factors and specifications of solar dish technologies for different systems and applications, Renewable and Sustainable Energy Reviews, 67 pp. 1019-1036, 2017.

19. Ramalingam Senthil, Mukund Gupta and ChinmayaRath, Parametric analysis of a concentrated solar receiver with Scheffler reflector, International Journal of Mechanical and Production Engineering Research and Development, 7 (5), 2017, pp. 261268. 
